\title{
EVOLUTION OF HISTORICAL CLOTHING GIVING A TRUE ESSENCE TO FASHION ERA OF 21ST CENTURY
}

\author{
Chaitanya Choudhary \\ Enrollment No: 2018PUSDABFTX06563, \\ Poornima University, \\ Jaipur
}

\author{
Dr. Ankita Singh Rao \\ Asst. Professor, \\ Poornima University, \\ Jaipur
}

\begin{abstract}
Fashion is something which traces its footprints back from the history which involves all the techniques which are still followed in present world of fashion, and brings a glimpse of our history and culture which clearly state that from DIY to the Designer fashionable attire the old techniques are followed in same way with lots of adoration globally

This signifies fashion nova but unlike it never disappears and always stay in fashion that's why it's classic and adopted by all .Old fashion techniques which now a days are coming up with modern evolution not only this the vintage fashion and its techniques always stays in trend, fashion cycle keep revolving with the some new innovations but what stays the same is the basics of the fashion which now a days in a verge of today's fashion industry which is termed as "old fashion", " sustainable fashion" and it is continuous, worthwhile, renewable, viable and most importantly in vouge and this research paper revolves around going back to the old steps of fashion.
\end{abstract}

KEYWORDS: Fashion, Sustainable, Old, History, Designer, Traditional, Techniques, Trend, Vintage, Industry, Culture, Footprints, Globally 


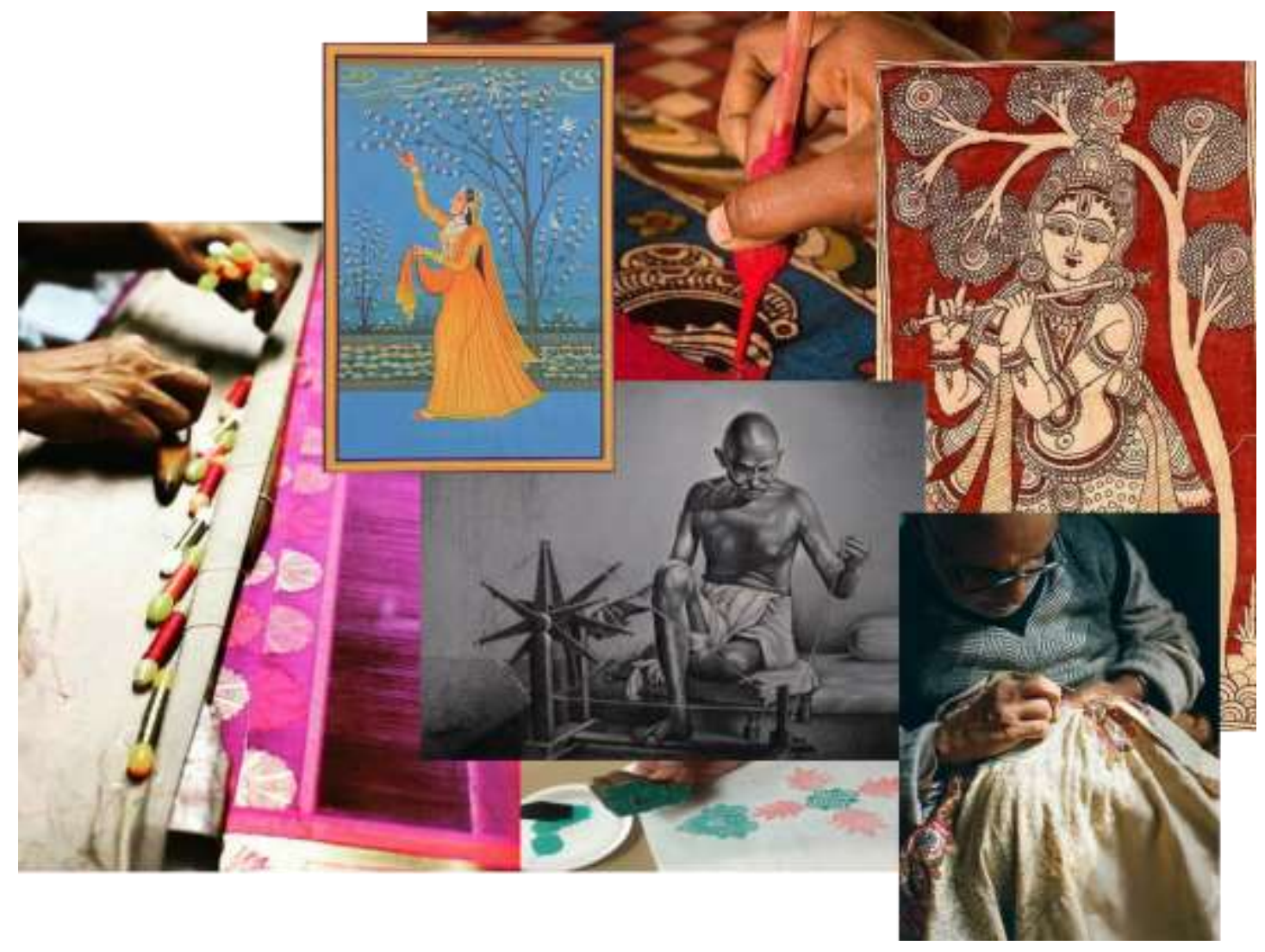

Image Source: Pinterest

\section{INTRODUCTION}

Fashion in India is introduced when the human civilization begins on this cultural land and it is very evident that the series of sustainable fashion was started here along with Indian's rich culture, history and different regions .Indian fashion is a collection of empires and decades of royalty and traditional techniques which passed on from generation to generation of different fashion trends that have recreated, redesign and relaunched with the same grace and gained the same acknowledgment as before. As in present scenario the Made in India is a campaign which is running in pace all over the nation and was promoted on global platforms the key of this campaign was to endorse the products manufactured in India. But in apparel industry it was going hand in hand which means manufactured in India along with sustainability because this concept is not new, to the Land of Gandhi our leaders and thinkers-initiated use of Swadeshi, organically grown fabrics for making attires with our Indian techniques.

Now coming back to the historic footprints of sustainable fashion in ancient India, clothes were mainly made from locally grown cotton during the Indus Valley Civilization, after the usage of homespun fabrics there are way more things in our history which shows how India was first among all to promote the sustainable fashion through its very own techniques which depicts the traditional elements using the natural components ,for exampleprinting tradition dating back to ages and India was the one to introduce a wide variety of textile arts with different method along with a unique output with significant process which means done by hand where the colors used are absolutely natural not only this we have intricate weaves, Indian embroideries, traditional art and craft. The agenda of this topic is to explain the Indian sustainable fashion techniques which are diverse yet distinct demonstration of our rich cultural heritage which are followed from the very beginning on the land of wonders that's why it one of the greatest treasures of the country which is Celebrated all over the world.

\section{HISTORIC REFERENCES}

Indian history is full of art, crafts and diversity of religions and culture that is proven to be a cherry on the top because it clearly complimented the Indian fashion history which are still continuing on with the same poise. let's quote the examples which showcase our history and fashion together, Indian surface works have gained popularity not only in Indian markets but International markets as well; Indian surface works are one among the gorgeous 
gifts the rich Indian culture has got to offer. However, these traditional handiworks also tell the story of Indian history, from the valleys of Kashmir to the ornate kingly apparel of Mughals, Nawabs, Rajputana's and Marathas; not only this if we take a long jump back then we have not one but diverse fashion era which is Vedic period, women wrapped themselves with a single cloth over their shoulder, pleated garment (paridhana), belt (mekhala) and a shawl fabric the shoulders (uttariya) Both men and women wore these clothes difference was the size and style of wearing and called as Vedic fashion, Gupta fashion period this era brought the stitching of garments which denoted royalty. Clothes could now be cut and sworn into beautiful garments, Mughal Empire, the king Akbar influenced the way people dress together with his distinct sort of dressing. It was a combination of the Hindu and Muslim culture, arts and was proven to be biggest fashion era which is now a days called as Mughal fashion after this comes the Post-independent Indian fashion era which has evolved to leave a distinctive mark on the world of fashion throughout the world. Even the traditional silhouettes like the sari, ghagra choli or dhoti still remain popular in the modern fashion scene. Indian attire is most famous for its intricate embroidery designs on the dresses, saris, skirts, shirts or shorts that have also incorporated western fashion. The history is proven that with its rich history and culture, Indian designs have stood for a huge time and have evolved to take the style world by wind of influence.

\section{Following the 3R's}

Rethink - India from the very beginning has its root indulged in fashion world but what makes its presence remarkable was its approach towards the sustainability, design, art and craft along with its basics which have always stick to the culture. Initially the idea of sustainable fashion was adopted by none other then the Indians beside this we are the inventors of many fashion techniques and style which are on the top of trend list and can not be replaced because its classic. India has always been a trend settler for the whole wide world and the reason behind this is designs which are created by us shows the glimpse of our imperial past. what makes our designs and techniques unique among all is that we have a procedure of working which says think $>$ evaluate $>$ finalize $>$ outcome and this cycle continues when we pick up the same process but we rethink and re-evaluate on the same thing as done before but come up with a different outcomes with the same idea and that idea is our culture and traditions which stays the same and this process of rethinking always outshine our traditions and culture in front of world but every time with a new interpretation and that is the key feature of our designs .

Reuse- Reusing was something which gives a loud call to sustainability specially in India for example reusing was a tradition of passing the richness and royalty, the bridal attire was passed from generation to generation of brides as it is a mark of family's culture same in this way, later on people started it understanding as a concept of reusing and utilizing the clothes, such as the fabric can be designed into different types of re-usable products not only to the local's but this is adopted globally by the top brands as it is seen as a shield to tons of textiles waste and a approach which brings a new life to something that's used which brings a new outlook within the people in a form of fashion revolution .

Redesign- Redesigning can be understood simply by the chain of relativity between all the aspects of fashion which clearly reflects the multiple elements and utility of the products. The fashion industry has undergone sweeping changes which brings lot of things together in one box which is reuse, recycle, evaluation and redesigning under the banner of sustainable fashion. For example - khadi was introduced in India and now a days it's on a verge of sustainable product material which is redesigned with modern silhouette in combination with Indian surface ornamentation techniques. Also, when view thoroughly the concept of redesigning can be seen in each and every house of India where mother sarees can be redesigned into various types of garments; Redesigning Fashion in India reveals the enrich perspective about sustainable fashion, inspired work from our traditional techniques and most importantly our primitive concepts which are succeeded all over the world.

\section{CO-RELATED WITH WORLD FASHION}

India has an immense creative side when it comes to fashion which is celebrated across the global market with acceptance and appearance. The practice of fusion wear goes both sides, it is a popular fashion choice in India too. A collection of western outfit with either folk prints or vice versa is in popular demand today. So, this Indian concept of sustainability with traditional techniques reflects fusion with diversity and have come up with bright hues and big Indian prints this Indian picture of fashion shows the origin of our long-established appearance in the world of fashion. Indian approach towards the sustainable fashion has given our craftsmen a chance to put forward their skills and earn their livelihood this also helped in promoting Indian culture and crafts that inculcated only in our country. Today, after years, history is repeating itself as Indian designers are echoing the same and because of this we are working in joint ventures with international brands and the products which we have created in collaboration are both unique and contemporary and are in huge demand internationally which has given a boom to Indian apparel industries 
supply and demand chain which created a huge profit in favor of local Indian brands.

\section{DESIGNER OUTLOOK TOWARDS SUSTAINING OLD FASHION}

As we know designers are the source who work as presenters to showcase the country fashion in front of world at different platforms, Indian fashion designers have raised the bar of the country on a global level and are renowned around the globe for their unique and innovative designs and in this series of designers Ritu Beri was the first Indian Designer who showcase a collection in Paris, Her design represents a rare sense of eminence and luxe richness of India which proved to be a glorifying period for Indian industries as it was the first step in international market not only this there are multiple designers and their fashion label's which are working on sustainability along with Indian textiles and techniques, contributing in our Indian fashion industry. Example- Shift by Nimish Shah, Ka Sha by Karishma Shahani, Grassroot by Anita Dongre, Eka by Rina Singh are some designer labels.

As per designers, garment is constructed with a series of story line which are crafted with contemporary designs, combinations of colors and embroideries along with traditional techniques, prints ,textiles and all of this is done while keeping sustainability in preference .Our young, forwardthinking Indian designers work goes beyond beautiful design and highlights fair practices, social responsibility, and environmental sustainability elements that truly set their creations apart which are inspired by rich heritage, showcasing Indian aesthetics with a modern sensibility. This proves that our designers are creating new way towards sustainable fashion approach which is followed by all national and international designers worldwide.

\section{CONCLUSION}

Indian fashion has always stand out among all the fashion industries within the world. India has an old-charm fashion which is adopted by all. India has given the world a creation sphere of heritage, traditions, folk love about the cultural aura of its own fashion which itself features a historic foundation because its style is the most running fashion segment not only this, India has been a muse to the international fashion. This cultural land from the very beginning putting things together because it's sheer amount of diversity, techniques, art, crafts and history from each and every region is immense, and no other country can come near to it.

From king's dynasty till our leaders this land has always promoted the sustainable fashion and therefore the plus point about its years and years passed but its richness, elegance and artistic elements has remained identical and preserved by its people and promoters. Our designers and craftsmen are inspiration for other designers as they showcase the way to design without losing your roots; they're the developers of this redefining age of fashion. Lastly "Fashion has always been a part of classic time costume \& techniques which reflects the magnificent era".

\section{REFERENCES}

Bibliography: History of Indian Costume(https://www.scribd.com/document/2401386 91/History-of-Indian-Costume)

\section{webliography}

https://en.wikipedia.org/wiki/History of clothing in the Indian subcontinent

https://www.thehindu.com/life-and-

style/fashion/runway-to-green-sustainable-fashion-inindia/article22704341.ece,

https://textilevaluechain.in/2019/07/12/indianheritage-an-inspiration-for-international-fashion/ https://artsandculture.google.com/story/gwLyN zpPN1Lg. 